\title{
The Research on Asynchronous Motor Electronic Load
}

\author{
Guixiu Jiang \\ Key Laboratory of Renewable Energy \\ Chinese Academy of Science \\ Guangzhou, China \\ jianggx@ms.giec.ac.cn
}

\author{
Jie Shu \\ Guangzhou Institute of Energy Conversion \\ Chinese Academy of Science \\ Guangzhou, China \\ shujie@ms.giec.ac.cn
}

\begin{abstract}
The electronic load is used to simulate the asynchronous motor and its load, making up the shortage of classic physical simulation method. The equivalent model of asynchronous motor is discussed. Combining the equivalent circuit with the rotor equation of asynchronous motor, the asynchronous motor model is built up. With the asynchronous motor model and the electronic load based on PWM, the asynchronous motor electronic load model is obtained. The simulation results of asynchronous motor drugging different kinds of load are obtained in the events that in starting, in steady state, with disturbances on power supply side and load side. The design with electronic load in the field of circuit control is proved to be correct and feasible.
\end{abstract}

Keywords- electronic load; the asynchronous motor; dynamic physical simulation

\section{INTRODUCTION}

There are various types of power system load, such as electrothermal load, lighting load, rectifying load, the synchronous motor, the asynchronous motor, and so on. It's difficult to simulate the character of the asynchronous motor exactly, which is one of most important load. The classic physical simulation used in dynamic physical simulation is an approximation method, so that the electric motor simulators with different capacities have to be provided, and there are shortcomings that the parameters are hard to adjust, the cost is increased, and so on. If the electronic load can be used in the dynamic physical simulation of asynchronous motor character and load characteristic of electric drive, the shortages can be make up for that the method and condition of experiment are flexible, the parameters can be adjusted easily, and the cost is decreased ${ }^{[1][2]}$.

The essence of electronic load is to simulate a classic load with a power electronic convert. So that, the electronic load can replace the real impedance load when the input current of electronic load can be precise controlled and has the same character with real impedance load ${ }^{[3][4]}$. Although the electronic load can't take over the classic load yet ${ }^{[5][6][7]}$ the theoretical basis of its application in asynchronous motor simulation is adequate. The asynchronous motor electronic load and its concrete model realization are discussed here.

\section{EQUIVALENT ASYNCHRONOUS MOTOR MODEL}

The exact asynchronous motor simulation using the electronic load lies in the accuracy of reference current. So the equivalent asynchronous motor circuit is adapted to solve the power supply side command input current of Load simulation unit.

For the equivalent asynchronous motor which is driving a load, the input current of asynchronous motor can be got, when the terminal voltage is known, the parameters such as resistance and inductance of rotor, stator, and magnetizing branch are given.

Setting that the asynchronous motor with the insulated neutral has no zero sequence components, and the terminal voltage of asynchronous motor in dq 0 coordinate can be expressed as:

$$
\left\{\begin{array}{l}
v_{s d}=\frac{2}{3}\left(v_{s a} \sin \omega t+v_{s b} \sin \left(\omega t-\frac{2 \pi}{3}\right)+v_{s c} \sin \left(\omega t+\frac{2 \pi}{3}\right)\right. \\
v_{s q}=\frac{2}{3}\left(v_{s a} \cos \omega t+v_{s b} \cos \left(\omega t-\frac{2 \pi}{3}\right)+v_{s c} \cos \left(\omega t+\frac{2 \pi}{3}\right)\right.
\end{array}\right.
$$

where $v_{s a}, v_{s b}, v_{s c}$ are the values in abc coordinate, $\omega$ is the angular frequency of system.

The asynchronous motor voltage equation in dq0 coordinate can be expressed as:

$$
\left\{\begin{array}{l}
v_{s d}=p \psi_{d s}-\omega \psi_{q s}+r_{s} i_{d s} \\
v_{s q}=p \psi_{q s}+\omega \psi_{d s}+r_{s} i_{q s} \\
0=p \psi_{d r}-s \psi_{q r}+r_{r} i_{d r} \\
0=p \psi_{q r}+s \psi_{d r}+r_{r} i_{q r}
\end{array}\right.
$$

The slip ratio $S$ can be expressed as:

$$
s=1-\frac{n}{n_{0}}
$$

where $n$ is the real motor speed, $n_{0}$ is the synchronous speed.

The flux-linkage equations of asynchronous motor in dq0 coordinate can be expressed as: 


$$
\left\{\begin{array}{l}
\psi_{d s}=L_{s} i_{d s}+M i_{d r} \\
\psi_{q s}=L_{s} i_{q s}+M i_{q r} \\
\psi_{d r}=M i_{d s}+L_{r} i_{d r} \\
\psi_{q r}=M i_{q s}+L_{r} i_{q r}
\end{array}\right.
$$

The electromagnetic torque $T_{e}(\mathrm{~N} \cdot \mathrm{m})$ is

$$
T_{e}=i_{q s} \psi_{d s}-i_{d s} \psi_{q s}
$$

According to the Newton's second law, there is

$$
T_{e}-T_{L}=J \frac{d \omega}{d t}
$$

where $T_{L}(\mathrm{~N} \cdot \mathrm{m})$ is load torque, $J\left(\mathrm{~kg} \cdot \mathrm{m}^{2}\right)$ is rotary inertia, which is a constant corresponding to the specific motor, $\omega(\mathrm{rad} / \mathrm{s})$ is angular velocity of rotation.

By Solving the simultaneous Equation (2), (4), (5), (6), $i_{d s}$ and $i_{q s}$ can be got, and the Stator current of asynchronous motor in abc coordinate can be obtained through Equation (7):

$$
\left\{\begin{array}{l}
i_{a}=i_{d s} \sin \omega t+i_{q s} \cos \omega t \\
i_{b}=i_{d s} \sin \left(\omega t-\frac{2 \pi}{3}\right)+i_{q s} \cos \left(\omega t-\frac{2 \pi}{3}\right) \\
i_{c}=i_{d s} \sin \left(\omega t+\frac{2 \pi}{3}\right)+i_{q s} \cos \left(\omega t+\frac{2 \pi}{3}\right)
\end{array}\right.
$$

Combining the equivalent circuit with the rotor equation of asynchronous motor, the asynchronous motor model can be built up based on Matlab, as shown in Fig. 1.

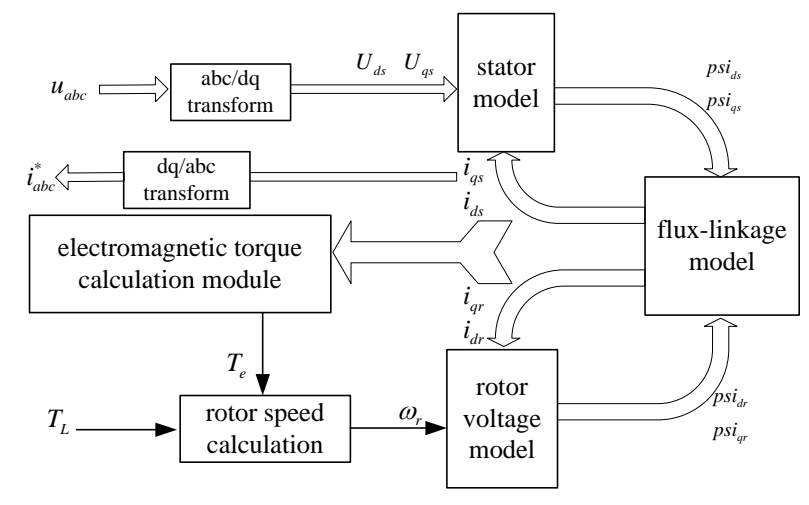

Figure 1. asynchronous motor model
The model is a differential equation with its solution procedure. Firstly, $i_{a}^{*}, i_{b}^{*}, i_{c}^{*}$ are estimated through Equation (2), (4), (7). Secondly, the electromagnetic torque can be got by Equation (5). Thirdly, the rotor speed ${ }^{n}$ can be obtained by Equation (6). Then, $i_{a}^{*}, i_{b}^{*}, i_{c}^{*}$ can be confirmed again based on the new value of rotor speed $n$.

\section{AsynCHRONOUS Motor ElECTRONIC LOAD MODEL}

The key point of asynchronous motor electronic load is to realize the input three-phase AC control of , so that its current characteristics are same as the actual motor when looking from the grid side. Combining the asynchronous motor model with the electronic load based on PWM, the whole asynchronous motor electronic load model can be obtained, as shown in Fig. 2.

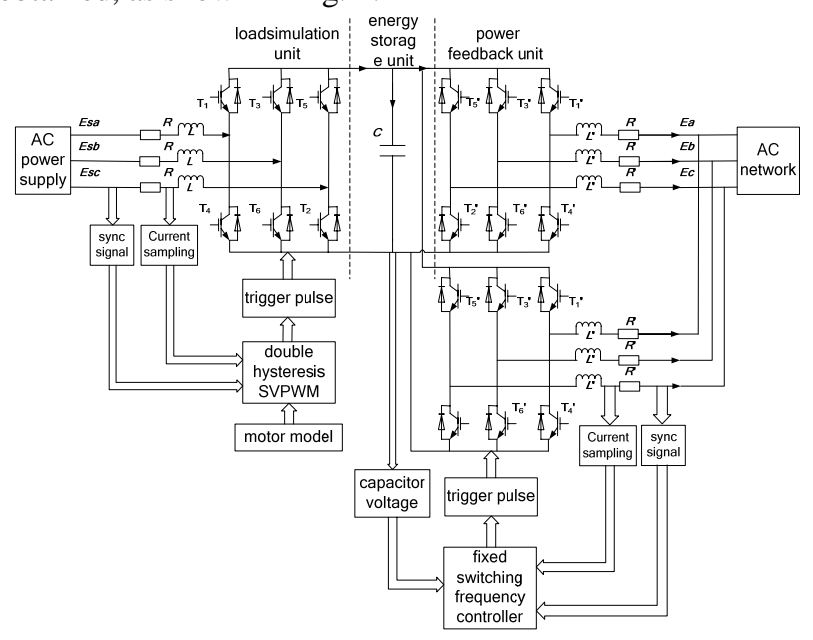

Figure 2. asynchronous motor electronic load model

The electronic load is designed based on the basic principles and topology of three-phase voltage type PWM rectifier ${ }^{[8][9]}$. The main circuit is a DC-AC-DC back to back system. It is composed of three units used for load simulation, energy store and feedback respectively.

In the load simulation unit, three-phase voltage source PWM rectifier consists of full-controlled switch $T 1-T 6$, whose main function is to control the input current to track the reference current rapidly and accurately, so that variety of load characteristic simulation, such as balanced, unbalanced, nonlinear, and dynamic loads, can be realized. The capacitor $C$ is the main component of the electric energy storage unit. The energy feedback unit is similar to the load simulation unit, whose main function is the control of the output current, making the energy absorbed can back to the grid through the inverter efficiently, while maintaining a constant DC bus voltage.

The starting current of induction motor is large and changes quickly. However, the electric energy storage unit can just absorb a certain part of current because of the capacitor DC voltage and PWM modulation rate limitations. By improving the DC voltage, the PWM modulation voltage range can be expanded, but the harmonics of absorption 
current and feedback current will increase, and the higher the pressure resistance of the IGBT is required. For this case, the shunt principle is used by combining the independent voltage-type PWM converters in parallel in power feedback unit, and the phase shift PWM is applied in the control system, so that the capacity of simulator and the output current waveform are improved.

\section{SIMULATION AND ANALYSIS}

The parameters of asynchronous motor are set:

$$
\begin{gathered}
R_{1}=1.375 \Omega, R_{2}=1.047 \Omega, R_{m}=8.34 \Omega, \\
L_{1}=0.0077349 \mathrm{H}, L_{2}=0.0140058 \mathrm{H}, \\
L_{m}=0.262924 \mathrm{H},
\end{gathered}
$$

The rotary inertia is $J=0.25 \mathrm{~kg} \times \mathrm{m}^{2}$,

The number of pole-pairs is $p=4$.

The tests on asynchronous motor electronic load include simulation of no-load starting, starting with load, power interference and load disturbances, and the results are shown as fellow:

The motor was no-load starting, load torque $T_{L}=0$, the results are shown as Fig. 3.

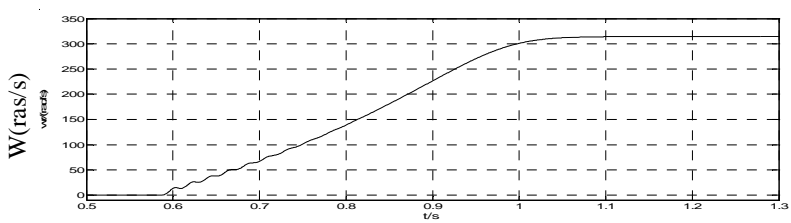

$\mathrm{t} / \mathrm{s}$

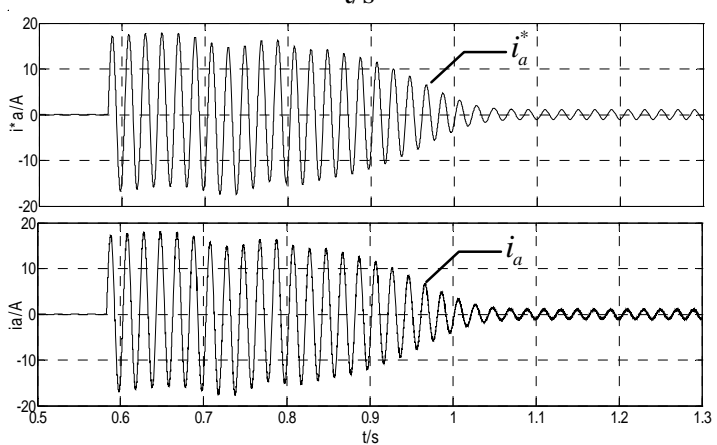

$\mathrm{t} / \mathrm{s}$

Figure 3. the no-load starting character simulation form

The motor started with load, load torque $T_{L}=1 \mathrm{~N} \cdot \mathrm{m}$, the results are shown as Fig. 4.

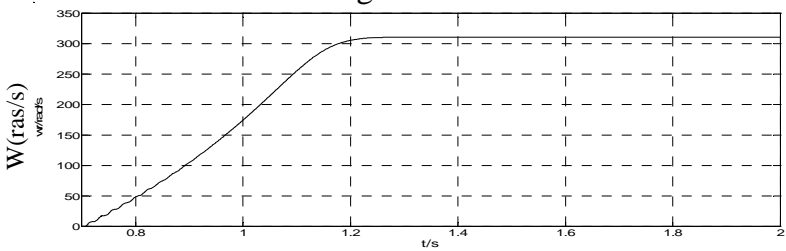

$\mathrm{t} / \mathrm{s}$

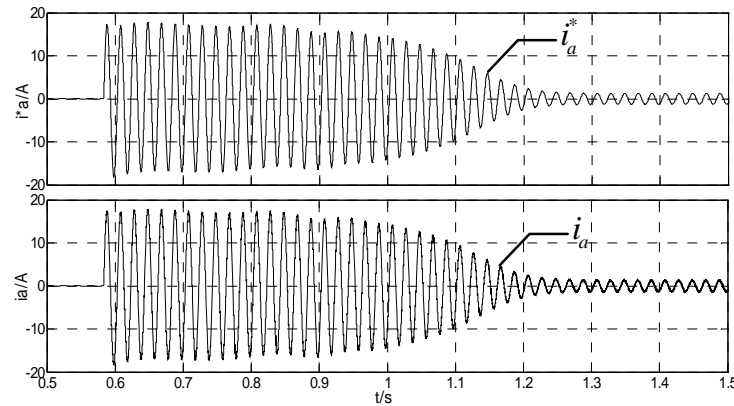

Figure 4. the starting $\mathrm{w}_{\text {_._._. }} \mathrm{t} / \mathrm{s}$ _. character simulation form

Fig. 3 and Fig. 4 show the waveform graphs of real value and command value of a phase stator current in power supply side, and the angular velocity of rotation from top to down.

As shown in the waveform graphs, no matter in the condition of no-load starting or starting with load, the waveform of power supply side input current of Load simulation unit is almost same as the command current waveform, the angular velocity increases gradually and keeps be about 320rad/s. It shows that the electronic load can preferably simulate the no-load starting and starting with load characteristic of asynchronous motor.

The power interference of load simulation unit occurred at 1.4 second, when the power voltage changed from $220 \mathrm{~V}$ to $250 \mathrm{~V}$ abruptly, the constant torque load is drove by asynchronous motor, and the results are shown as Fig. 5.
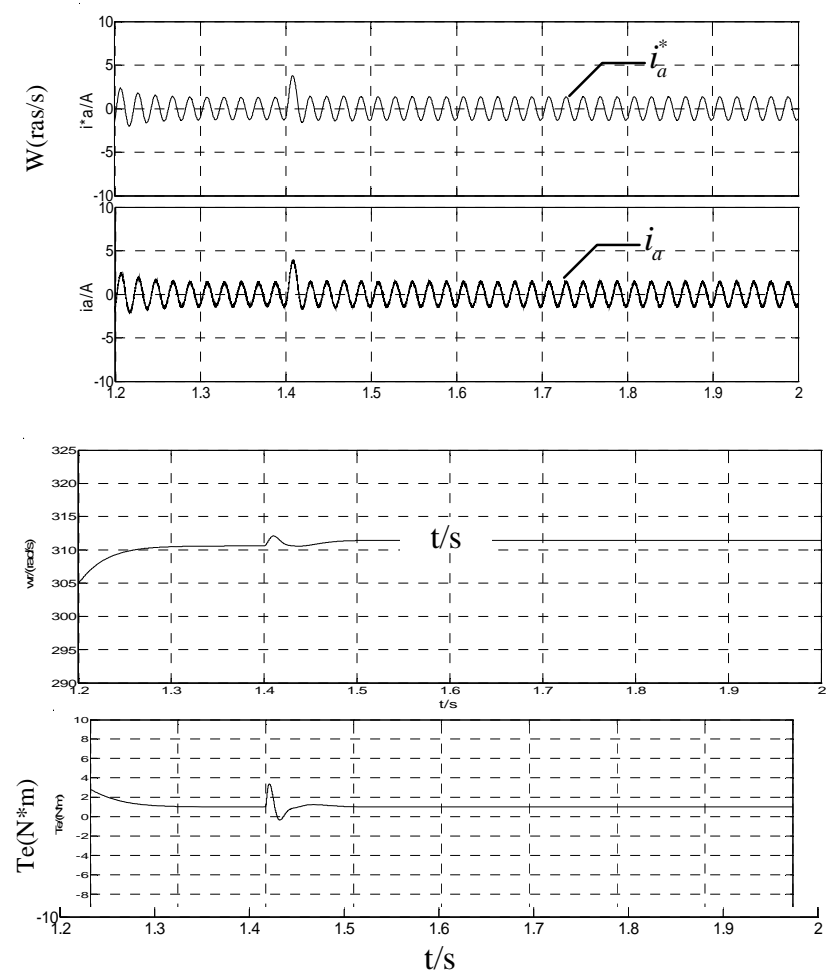

Figure 5. the power interference character simulation form 
The load disturbance occurred at 1.4 second, when the load torque $T_{L}$ changed from $1 \mathrm{~N} \cdot \mathrm{m}$ to $5 \mathrm{~N} \cdot \mathrm{m}$, the results are shown as Fig. 6.
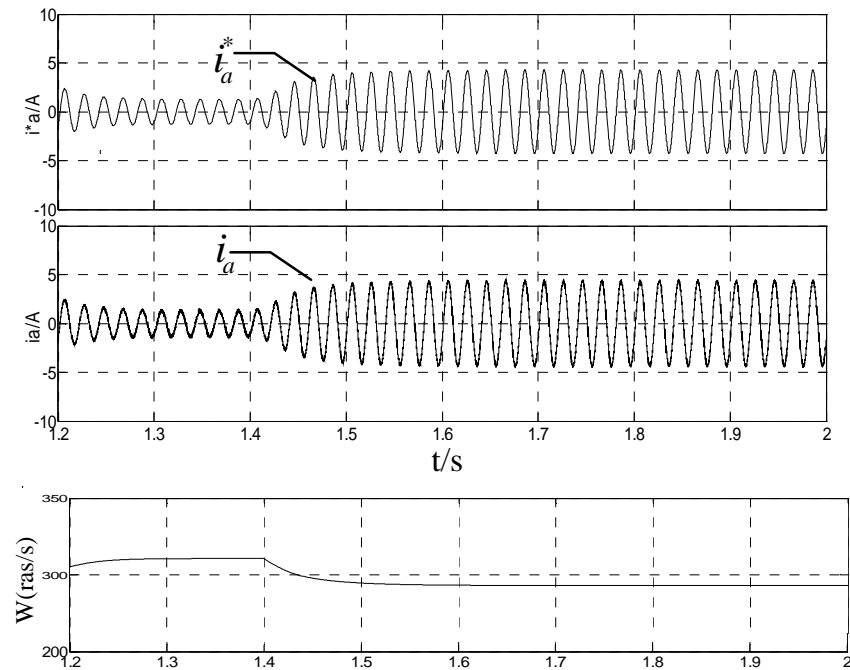

$\mathrm{t} / \mathrm{s}$

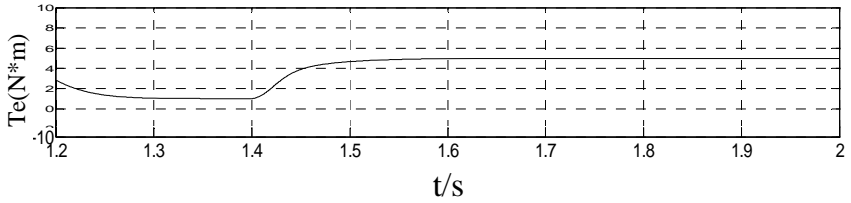

Figure 6. the load disturbances character simulation form

Fig. 5 and Fig. 6 show the waveform graphs of real value and command value of a phase stator current in power supply side, the angular velocity of rotation, and the electromagnetic torque from top to down.

As shown in Fig. 5, the waveform of power supply side input current of Load simulation unit can follow the command current waveform quickly, the angular velocity increases as the real angular velocity of motor; the electromagnetic torque resumes to the original value after the fluctuation proving that the constant torque load is being drove. It shows that the electronic load can preferably simulate the asynchronous motor characteristic when there is power interference.

In Fig. 6, the waveform of power supply side input current of Load simulation unit can follow the command current waveform quickly, the angular velocity decreases and then keeps steady, the electromagnetic torque increases and then keeps steady. It shows that the electronic load can preferably simulate the asynchronous motor characteristic when there is load disturbance.

\section{CONCLUSION}

The asynchronous motor electronic load for dynamic physical simulation of power system is discussed.
Combining the equivalent circuit with the rotor equation of asynchronous motor, the asynchronous motor model is built up, consisting of the asynchronous motor model and three types of mechanical loads models. Based on the asynchronous motor model and the electronic load, the asynchronous motor electronic load model is obtained. The tests on asynchronous motor electronic load including simulation of no-load starting, starting with load, power interference and load disturbances are taken. The results show that the waveform graphs of each parameter are almost consistent with the real motor, using the electronic load to simulate the asynchronous motor and its load is correct and feasible.

\section{ACKNOWLEDGMENT}

The authors are grateful for the financial support from National Natural Science Foundation (NO. 51206170); hitech district guide project of Guangdong Province (NO. 2112B0900023); Guangdong and Hong Kong tender project of Guangdong Province (NO. 2011BZ100101).

\section{REFERENCES}

[1] Zhao Jianfeng, Pan Shifeng, Wang Xun. "High Power Energy Feedback AC Electronic Load and Its Application in Power System Dynamic Physical Simulation”, Transactions of China Electrotechnical Society, 12(12), pp. 35-39, (2006)

[2] ZHANG Chunjiang, GUO Zhongnan, WANG Qin, XU Dianguo. "Analysis of Bi-direction Operation State of Three Phase PWM Rectifier Based on a New Phase and Amplitude Control”, Proceedings of the CSEE, 26(11), pp. 161-167, (2006)

[3] Guar-Chyun Hsieh, Jung Chien Li. "Design and Implementation of An AC Active Load Simulator Circuit", IEEE Transactions on Aerospace and Electronic Systems, 29(3), pp. 157-165, (1993)

[4] Chin-E Lin, Ming-Tsung Tsai, Wen-Inne Tsai, etal. "Consumption Power Feedback Unit for Power Electronics Burn-in Test”, IEEE Transactions on Industrial Electronics, 44(2), pp. 157-166, (1997)

[5] Chu C L, Chen J F. "Self-load bank for UPS testing by circulating current method”, Electrical Power Application, IEE Proceeding, 141(4), pp. 191-196, (1994)

[6] Ayres C A, Barbi I. "A family of converters for power recycling during UPS's burn-in test”, IEEE PESC’95, 26(1), pp. 486-492, (1995)

[7] Huang S J, Pai F S. "Design and operation of burn-in test system for three-phase uninterruptible power supplies”, IEEE Transaction on Industrial Electronics, 49(1), pp. 256-263, (2002)

[8] Jiang Guixiu, Zhang Bingda, Wang Chengshan. “Application of fuzzy logic control in power load simulator", 7th IET International Conference on Advances in Power System Control, Operation and Management, APSCOM 2006

[9] Jiang Guixiu, Zhang xiaolei. "Application of voltage space vector PWM in electronic load”, 2009 Asia-Pacific Power and Energy Engineering Conference, APPEEC 2009 - Proceedings

[10] Xie Mingjing, Jin Shun, Zhong Yanru. “An Alterable Electronic Load of Asynchronous Electromotor in the Full Velocity Range”, The World of Inverters, 11, pp. 51-53, 16, (2005) 